\title{
Effect of Prostacyclin on Vascular Capacity in the Dog
}

Thomas G. Fulghum, John P. DiMarco, Edward W. Supple, Ira Nash, Joseph Gendlerman, Darwin F. Eton, John B. Newell, Randall M. Zusman, and Wm. John Powell, Jr. Cardiac Unit of the Massachusetts General Hospital, and Departments of Medicine of Massachusetts General Hospital and Harvard Medical School, Boston, Massachusetts 02114

\section{Abstract}

Since the discovery of prostacyclin $\left(\mathbf{P G I}_{2}\right)$ in 1976, there has been great interest in its vascular effects and potential clinical applications. High infusion rates of $\mathbf{P G I}_{2}$ markedly depress arterial blood pressure both in animal studies and in clinical trials. This fall in pressure may result entirely from a decrease in arterial resistance. However, it is possible that the administration of $\mathbf{P G I}_{2}$ may decrease ventricular filling due to an increase in vascular capacity. To investigate whether or not $\mathbf{P G I}_{2}$ affects vascular capacity, we infused PGI $_{2}$ intraarterially at both 10 and $25 \mu \mathrm{g} / \mathrm{min}$ into $15 \mathrm{dogs}$ on total cardiopulmonary bypass. These infusions were associated with a $25 \pm 3 \mathbf{~ m m H g}$ decrease in arterial pressure and an increase in vascular capacity of $155 \pm 29 \mathrm{ml}$ (SE, $P<0.005)$. This increase in capacity was greater $(P<0.02)$ than the increase of $23 \pm 42 \mathrm{ml}$ resulting from infusions of nitroglycerin into eight dogs at $2 \mathrm{mg} / \mathrm{min}$, which produced a decrease in arterial pressure of $23 \pm 4 \mathrm{mmHg}$, which was the maximal effect that could be achieved. Neither bilateral cervical vagotomy nor beta adrenergic blockade with propranolol significantly diminished the increase in vascular capacity associated with infusions of $\mathbf{P G I}_{2}$. The results from studies in four eviscerated dogs indicated that $\mathbf{P G I}_{2}$ acts on both splanchnic and extrasplanchnic capacity vasculature.

To compare the direct effects of $\mathbf{P G I}_{2}$ with those of nitroglycerin and nitroprusside on venous tone, we used an isolated canine spleen preparation. Infusions of $\mathrm{PGI}_{2}(100 \mathrm{mcg} / \mathrm{min})$ increased spleen weight in this preparation by $9.0 \pm 2.4 \%(n=10$, $P<0.001)$; this increase was significantly greater than increases of $3.6 \pm 2.2 \%(P<0.001)$ and $3.5 \pm 2.3 \%(P<0.001)$ caused by high dose infusions of nitroglycerin $(1 \mathrm{mg} / \mathrm{min})$ and nitroprusside (400 $\mu \mathrm{g} / \mathrm{min})$, respectively.

Thus, $\mathbf{P G I}_{2}$ substantially increases vascular capacity by a mechanism that appears to involve a direct action on vascular smooth muscle. Furthermore, these results suggest that $\mathbf{P G I}_{\mathbf{2}}$ might be useful in clinical conditions in which an increase in vascular capacity is indicated.

Dr. Fulghum was supported by a fellowship from the Stanley J. Sarnoff Endowment for Cardiovascular Research. This work was done during Dr. Zusman's tenure as an Established Investigator of the American Heart Association. Dr. Supple was a fellow of the American Heart Association, Massachusetts Affiliate. Address reprint requests to Dr. Powell, Cardiac Unit, Massachusetts General Hospital.

Received for publication 16 March 1984 and in revised form 3 May 1985.

J. Clin. Invest.

(C) The American Society for Clinical Investigation, Inc.

0021-9738/85/09/0999/08 \$1.00

Volume 76, September 1985, 999-1006

\section{Introduction}

Since the discovery of prostacyclin $\left(\mathrm{PGI}_{2}\right)^{1}$ (epoprostenol) by Bunting et al. (1) and Moncada and Vane (2) in 1976, a variety of effects of this agent on the cardiovascular system have been described $(1,2)$. The finding that $\mathbf{P G I}_{2}$ is the most potent known endogenous inhibitor of platelet aggregation suggests its possible use in reducing the deposition of platelets and fibrin on the filter mesh in patients undergoing operations with cardiopulmonary bypass (3-6). As an antiplatelet agent, $\mathrm{PGI}_{2}$ can successfully replace heparin as the sole antithrombic agent in patients with renal failure undergoing hemodialysis $(7,8)$. Its administration is associated with neither anticoagulation nor hemorrhage (7). However, in the latter study, symptomatic hypotension occurred in all cases, and in two patients necessitated termination of dialysis because of precipitous decreases in blood pressure.

With regard to the hemodynamic effects of $\mathrm{PGI}_{2}$, it has been established that this agent relaxes most in vitro vascular preparations, including rabbit mesenteric arteries, bovine coronary arteries, and human cerebral arteries $(1,9,10)$, and reduces systemic vascular resistance. This vasodilating action has therapeutic potential. For example, beneficial effects of $\mathrm{PGI}_{2}$ have been demonstrated in patients with pulmonary hypertension (11-14), peripheral ischemic vascular disease (15-19), and unstable angina (20). Furthermore, the increase in tissue conductance, which is the reciprocal of vascular resistance, particularly in the splanchnic circulation, coupled with the augmentation of cardiac output, which has been established experimentally, provides rationale for the use of $\mathrm{PGI}_{2}$ in the management of congestive heart failure (21). Yui and coworkers (22) have recently demonstrated that the infusion of $\mathrm{PGI}_{2}$ in nine patients with severe congestive heart failure resulted in a significant decrease in mean aortic pressure, systemic vascular resistance and pulmonary capillary wedge pressure, and a significant and substantial increase in cardiac output.

Thus, $\mathrm{PGI}_{2}$ has a potential role during the use of extracorporeal circulation but produces hypotension. Its vasodilator properties, on the other hand, give it potential in the treatment of conditions of decreased arterial perfusion and in the treatment of congestive heart failure. Studies to date have focused on the arterial circulation, and little is known about the effects of $\mathrm{PGI}_{2}$ on systemic vascular capacity. This latter effect may contribute to the overall hemodynamic effects produced by the administration of this agent. Vascular capacity determines venous return, ventricular filling and, thus, cardiac performance. Therefore, the present study was carried out to determine whether $\mathbf{P G I}_{2}$ alters vascular capacity, to localize the changes observed, and

1. Abbreviation used in this paper: $\mathbf{P G I}_{2}$, prostacyclin. 
to compare the effects of $\mathrm{PGI}_{2}$ on vascular capacity with those of nitroglycerin, a commonly used venodilating agent.

\section{Methods}

68 mongrel dogs weighing between 17 and $25 \mathrm{~kg}$ were anesthetized with chloralose $(60 \mathrm{mg} / \mathrm{kg}$ i.v.) and urethane $(600 \mathrm{mg} / \mathrm{kg}$ i.v.). The animals were ventilated with a Bird Mark 7 constant pressure respirator (Bird Corp., Palm Springs, $\mathrm{CA}$ ) using $97 \% \mathrm{O}_{2}$ and $3 \% \mathrm{CO}_{2}$. A right lateral thoracotomy was performed and a total cardiopulmonary bypass preparation, which has previously been used in our laboratory to study vascular capacity $(23,24)$, was used (Fig. 1). After heparin administration $(3 \mathrm{mg} /$ kg i.v.), the femoral veins and superior vena cava were cannulated and the azygos vein ligated. The inferior vena cava was ligated below and cannulated above the liver so that inferior vena cava blood flow reflected only hepatic venous return. Central venous pressure, measured in the venous return line of the pump oxygenator, was set at $8 \mathrm{~cm} \mathrm{H}_{2} \mathrm{O}$ before each experiment by adjusting the height of an overflow column. Venous blood was returned to a Harvey bubble oxygenator and heat exchanger (model H-1000, C. R. Bard, Inc., Santa Ana, CA). A roller pump (Cardiovascular Instruments, Wakefield, MA) returned oxygenated blood to the femoral arteries at a constant rate for each experiment, such that arterial pressure was $75 \mathrm{mmHg}$ for the control period. The aorta and pulmonary hila were cross-clamped to exclude the pulmonary, coronary, and bronchial circulations. The oxygenator reservoir was calibrated with whole blood in $100-\mathrm{ml}$ increments before each experiment so that a change in the animal's total vascular capacity could be measured as the reciprocal of a change in oxygenator volume. We infused $\mathrm{PGI}_{2}$ or nitroglycerin into the arterial inflow line using a constant infusion pump (model 600-900-S, Harvard Apparatus Co., Dover, MA). Infusion rates of $\mathrm{PGI}_{2}(10-25 \mathrm{mcg} / \mathrm{min})$ and nitroglycerin $(2 \mathrm{mg} / \mathrm{min})$ were chosen after preliminary experiments indicated that these rates produced maximal effects on arterial pressure and vascular capacity. $\mathrm{PGI}_{2}$ was dissolved

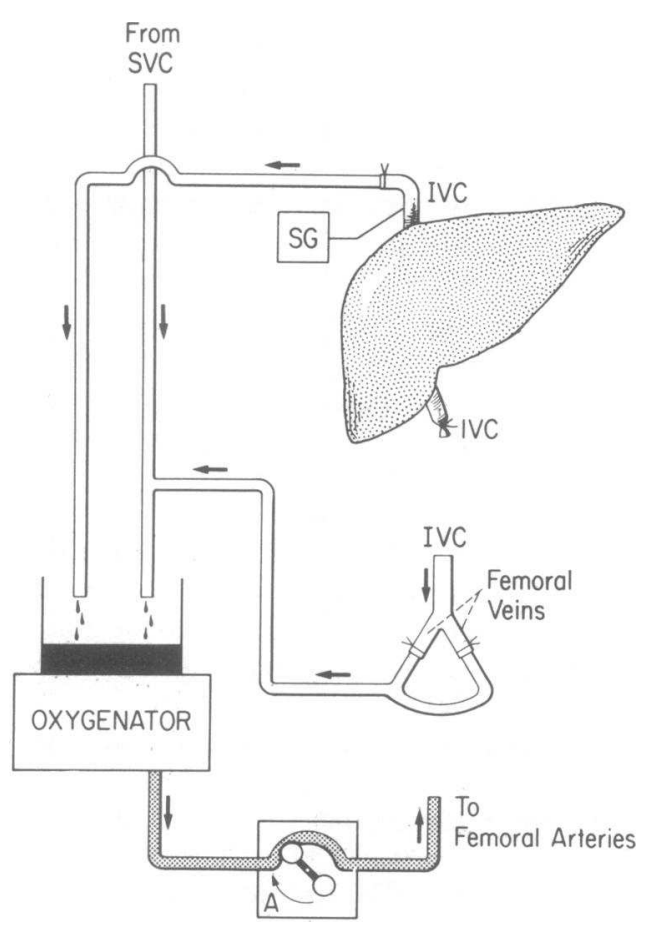

Figure 1. Schematic drawing of the total bypass preparation. Animals were perfused at a constant rate through the femoral arteries. Venous blood returned to the oxygenator through one line from the superior vena cava (SVC) and femoral veins and through a separate line from the inferior vena cava (IVC) above the liver. SG, strain gauge. in $20 \mu \mathrm{M}$ glycine buffer at pH 10.5; infusions of the glycine buffer alone affected neither arterial pressure nor vascular capacity.

Pressures were monitored with Statham $\mathrm{P} 23 \mathrm{Db}$ pressure transducers (Statham Instruments, Inc., Oxnard, CA); the frequency response of the pressure measurement system was linear up to 30 cycles per second. Arterial pressure was measured through a cannula placed in the left brachial artery and portal venous pressure was measured from a cannula inserted directly into the portal vein. All measured pressures were recorded on a Hewlett-Packard 7700 eight channel recorder (Hewlett-Packard Co., Waltham, MA).

Venous return from the hepatic venous line was collected manually for $15 \mathrm{~s}$ at 1 -min intervals in a graduated cylinder. We calculated transhepatic vascular resistance by dividing the difference between portal and hepatic vein pressures by hepatic venous outflow.

We administered propranolol (Inderal, $0.5 \mathrm{mg} / \mathrm{kg}$, Ayerst Laboratories, New York City) intravenously to five dogs to achieve beta adrenergic receptor blockade. The adequacy of blockade was confirmed by the near absence of an arterial pressure response to isoproterenol (Isuprel, 6,12 , and $24 \mu \mathrm{g}$ i.v., Winthrop Laboratories, New York City) after propranolol administration. To assess whether stimulation of the vagus nerves contributed to changes in vascular capacity, we performed bilateral cervical vagotomies in three animals. We removed the spleens from four animals to determine whether the spleen contributes to changes in vascular capacity. In these four dogs, all arteries and veins to the spleen were securely ligated and the spleen was excised. Four dogs were eviscerated before $\mathbf{P G I}_{2}$ infusion. The cranial and caudal mesenteric arteries and veins and the celiac axis were ligated, and the splanchnic organs (stomach, liver, spleen, mesentery, small intestine, and colon) were removed. In two dogs, the cranial and caudal mesenteric arteries and the celiac artery were cannulated and separately perfused to prevent redistribution from the splanchnic circulation during $\mathbf{P G I}_{2}$ infusion. The carotid and aortic baroreceptors were denervated in two dogs, and in two other dogs, ganglionic blockade with $150 \mathrm{mg}$ of mecamylamine (Inversine, Merck, Sharpe \& Dohme, West Point, PA) was administered before infusions of nitroglycerin. Denervation was confirmed by the absence of an arterial response to bilateral carotid artery clamping.

When dogs are placed on total cardiopulmonary bypass the oxygenator, blood volume progressively falls; this reduction, in the absence of interventions is linear over time $(23,24)$. Computer-assisted regression lines were drawn through the control period and the lines were extrapolated for oxygenator blood volume throughout the study as previously described (24). Changes produced by an intervention were measured as the differences between the extrapolated regression line and the observed oxygenator volumes.

The justification of this extrapolation was verified in 10 additional experiments, all with 11 distinct, equally spaced sample points in a 10min control period. Straight lines were fit to the control period points and variances in the estimated regression lines were computed for each minute post control out to the full 20-min experimental protocol. The standard estimates for variance in the prediction of a population regression line were employed (25). These minute by minute variance estimates, which result in hyperbolic confidence belts around the straight line which is extrapolated from the control period into the experimental period, were then pooled across all 10 experiments at each minute using the standard method for pooling variance estimates from independent sources (26). The pooled minute by minute variance estimates were then used to construct confidence limits $(6-7 \%, \pm \mathrm{SEM})$ about the $\mathrm{X}$ axis of the hypothetical zero change in volume.

10 additional dogs were prepared such that the action of vasodilating agents on the isolated spleen could be compared. In these animals, catheters were placed via the right femoral artery and vein into the aorta and the inferior vena cava for the pressure measurements. The abdomen was opened through a left subcostal incision and the spleen was exteriorized. The main splenic artery and vein were isolated, and all collateral vessels were ligated. One end of a large-bore polyethylene tubing was inserted into the left femoral artery, passed through a roller pump, and the other end inserted into the splenic artery, allowing total splenic perfusion via the external pump. A second polyethylene catheter was inserted into the 
splenic vein and brought to an overflow column set $13 \mathrm{~cm}$ above the splenic hilum. Pressure was continuously monitored in both the splenic artery and splenic vein catheters. Splenic artery flow was maintained between 40 and $45 \mathrm{ml} / \mathrm{min}$ and saline was administered to the animal via a peripheral vein to maintain a central venous pressure between 0 and $2 \mathrm{~cm} \mathrm{H}_{2} \mathrm{O}$. The splenic vein effluent was allowed to return to the animal via a left femoral vein catheter except during drug infusions, when blood previously removed from the animal was used to replace the diverted splenic vein effluent. Thus, no drug reached the systemic circulation during infusions into the isolated spleen. The spleen was placed in a pan attached to a strain gauge that was calibrated to give readings accurate to within $2 \mathrm{~g}$. A heat lamp maintained splenic temperature that was constant, and a transparent cellophane tent prevented drying of the splenic capsule. The splenic perfusion was allowed to equilibrate for at least 30 min, during which $0.9 \%$ saline was infused through a side port of the splenic arterial line at $1 \mathrm{ml} / \mathrm{min}$. Animals that did not have stable systemic and splenic arterial pressures and a stable spleen weight during this time were excluded. Each spleen was infused with the following three drugs in random sequence: nitroprusside (Nipride, HoffmanLaRoche, Inc., Nutley, NJ), $400 \mathrm{mcg} / \mathrm{min}$; nitroglycerin, $1 \mathrm{mg} / \mathrm{min}$; and $\mathrm{PGI}_{2}, 100 \mu \mathrm{g} / \mathrm{min}$. These doses produced similar and maximal splenic arterial pressure reduction in this preparation. Each drug infusion was continued for $5 \mathrm{~min}$ and the maximum increase in spleen weight was used for the assessment of changes in venous capacitance. After each drug infusion the spleen was allowed to return to the control weight before the next infusion. Separate infusions of the suspension media (D5W for nitroglycerin and nitroprusside and glycine buffer for $\mathrm{PGI}_{2}$ ) did not affect splenic artery pressure or spleen weight.

Significance of measured parameters from control values in the total bypass preparations was determined by analysis of variance and covariance including repeated measures (27). Individual data points also were tested for significance using a double-tailed, paired $t$ test, as were data obtained from the isolated spleen preparations. Significance was assumed only if $P<0.05$.

\section{Results}

Six dogs on total cardiopulmonary bypass received infusions of $\mathrm{PGI}_{2}$ at $10 \mathrm{mcg} / \mathrm{min}$, and 9 dogs received infusions at $25 \mathrm{mcg} /$ $\mathrm{min}$. The mean increases in vascular capacity at $10 \mathrm{~min}$ of infusion for the 10- and $25-\mu$ g infusions were $162 \pm 52$ and $150 \pm 34$ $\mathrm{ml}$ (mean $\pm \mathrm{SE}$ ), respectively (Fig. 2). The corresponding decreases in arterial pressure at $10 \mathrm{~min}$ were $25 \pm 7$ and $25 \pm 2 \mathrm{mmHg}$. These results confirmed preliminary experiments indicating that these delivery rates produced maximal effects on both vascular capacity and arterial pressure; therefore, results of the 15 experiments were grouped together for further analyses.

Fig. 3 illustrates the hemodynamic data obtained from the

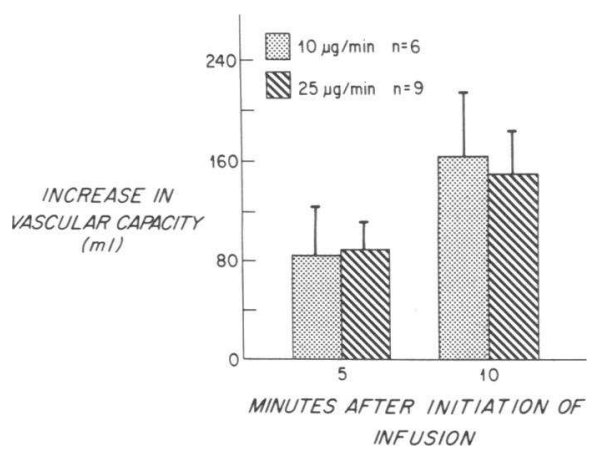

Figure 2. A comparison of the effects of $\mathrm{PGI}_{2}$ infusions at 10 and 25 $\mathrm{mcg} / \mathrm{min}$ on total vascular capacity. The increases in vascular volume at the two infusion rates were similar. 10-min infusions of $\mathrm{PGI}_{2}$. The top graph on the left shows the mean arterial pressure for the 15 experiments. Arterial pressure began to decrease at the onset of the infusion, stabilizing by $\sim 5$ min into the infusion at $\sim 25 \mathrm{mmHg}$ below control pressure. Arterial inflow, shown in the lower left graph, was set at a rate for each experiment, such that arterial pressure was $\sim 75 \mathrm{mmHg}$ during the control period, and the inflow rate was maintained constant during the infusion period. Portal venous pressure, in the upper right graph, varied slightly from animal to animal, but it did not change significantly during the infusion. The mean change in hepatic vein flow was $-4.9 \pm 12.4 \mathrm{ml} / \mathrm{min}$. Transhepatic vascular resistance did not change significantly during the infusion. Therefore, at constant arterial inflow and constant venous pressure the fall in arterial pressure reflects a decrease in arterial resistance resulting from infusion of $\mathrm{PGI}_{2}$. Since there was little change in hepatic vein flow in the above experiments, it is unlikely that arterial redistribution into the splanchnic bed accounts for the observed increase in vascular capacity. Two animals'with separate perfusion of the splanchnic arteries, so that redistribution could not occur, showed a gain in vascular capacity of 90 and $91 \mathrm{ml}$, which is similar to the results shown in the top panel of Fig. 4. Thus, redistribution does not account for the decreased change in vascular capacity resulting from $\mathrm{PGI}_{2}$ infusion.

The mean change in vascular capacity in 15 dogs that received infusions of $\mathrm{PGI}_{2}$ is shown in the top panel of Fig. 4. Capacity began to increase at the initiation of the infusion, and reached a mean increase of $155 \pm 29 \mathrm{ml}(P<0.005)$ at the end of the 10-min infusion.

Four animals were eviscerated to investigate whether the entire increase in vascular capacity occurred in either the splanchnic or peripheral capacity vasculature. At the end of a 10-min infusion of $\mathrm{PGI}_{2}$, vascular capacity increased by $74 \pm 27$ $\mathrm{ml}(P<0.001)$, which was significantly different $(P<0.02)$ from the mean increase of $155 \mathrm{ml}$ in the group not eviscerated (Fig. 5). Four dogs were splenectomized to be certain that the canine spleen, which has a muscular capsule, did not account for the entire increase in vascular capacity. Fig. 5 compares the mean increase in capacity in the splenectomized animals with the mean increase of the group that was not splenectomized. The mean increase in the four splenectomized dogs was $210 \pm 65 \mathrm{ml}$; this gain did not differ significantly from the mean increase in the intact group.

Five infusions were performed in three animals after bilateral cervical vagotomy, with two of the animals receiving second infusions. The middle panel of Fig. 4 shows that vascular capacity increased $195 \pm 47 \mathrm{ml}$ by the end of the infusions, compared with an increase of $155 \pm 29 \mathrm{ml}$ in the animals that were not vagotomized (NS). Five dogs received infusions after beta adrenergic blockade. As illustrated in the bottom panel of Fig. 4, the mean increase at the end of the infusion in the beta adrenergic blocked group was $89 \pm 72 \mathrm{ml}$; this change did not differ significantly from that in the unblocked group. One beta adrenergic blocked dog did not increase its capacity during the $\mathrm{PGI}_{2}$ infusion, and thus lowered the group mean. The other four beta adrenergic-blocked dogs, however, increased capacity by a mean of $159 \mathrm{ml}$; this increase was nearly identical to the increase of $155 \mathrm{ml}$ in the unblocked group.

Nitroglycerin was infused at $2 \mathrm{mg} / \mathrm{min}$, a dose which we determined produced maximal effects on arterial pressure and vascular capacity, in eight dogs on total cardiopulmonary bypass. The mean increase in vascular capacity of $23 \pm 42 \mathrm{ml}(\mathrm{NS})$ at the 


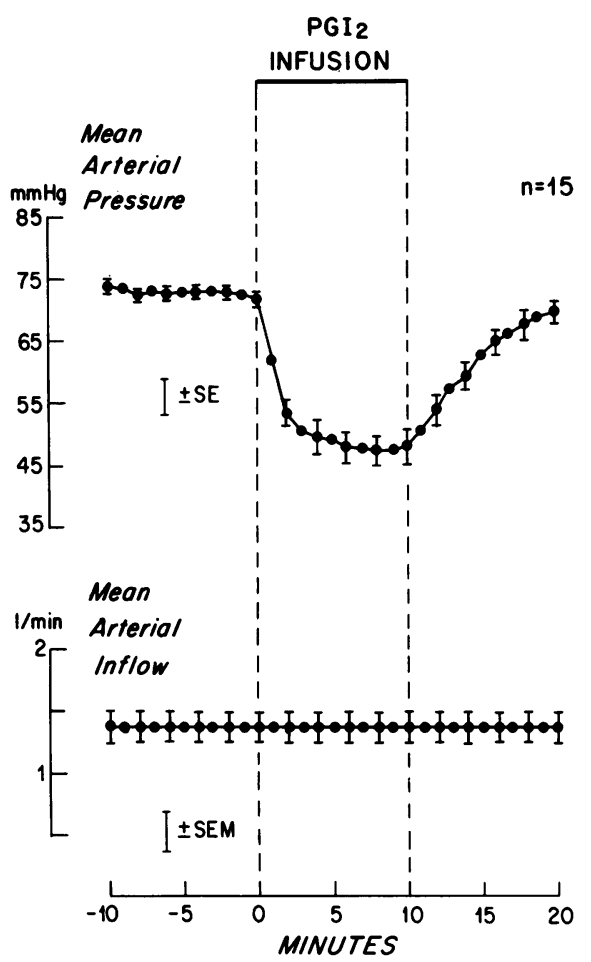

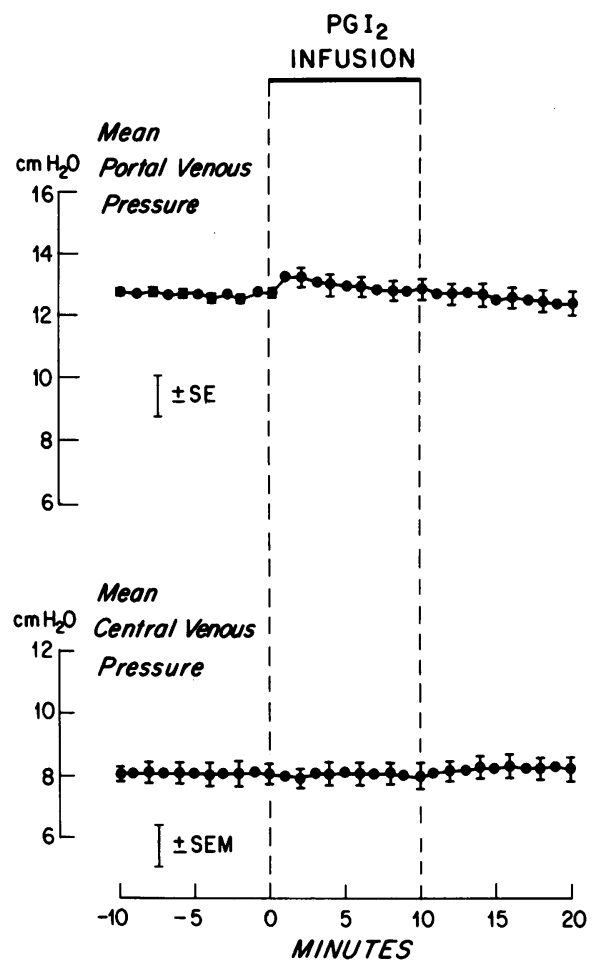

Figure 3. Mean data on the effects of 10-min intraarterial infusion of $\mathrm{PGI}_{2}$ in 15 animals. Arterial pressure decreased with the infusion of $\mathbf{P G I}_{2}$. Portal venous pressure did not change significantly during the infusions, and the arterial inflow and central venous pressure were maintained constant. end of the nitroglycerin infusions differed significantly $(P<0.02)$ from the mean increase of $155 \mathrm{ml}$ for the $\mathrm{PGI}_{2}$ infusions (Fig. 6). In three dogs where nitroglycerin was infused at $400 \mu \mathrm{g} / \mathrm{min}$, the increase in vascular capacity was only $13.3 \pm 23.3 \mathrm{ml}$, less than, but not significantly different from the higher dose infusion. The effect of nitroglycerin infusions on arterial pressure is compared with the effect of $\mathrm{PGI}_{2}$ in the bottom panel of Fig. 6. Arterial pressure in the control periods for the two groups was set at $75 \mathrm{mmHg}$. The maximum fall of $23 \pm 4 \mathrm{mmHg}$ in those animals receiving nitroglycerin closely approximated the maximum mean fall of $25 \pm 3 \mathrm{mmHg}$ in those infused with $\mathbf{P G I}_{2}$. After the initial drop in arterial pressure with infusion of nitroglycerin, the arterial pressure partially returned toward the control pressure. However, the arterial pressures of the three nitroglycerin-infused dogs with the largest decreases in arterial pressure at the end of the infusions were similar to the decreases associated with $\mathrm{PGI}_{2}$ infusions. Arterial pressures at the end of the nitroglycerin infusions in these animals were 20,21, and 27 $\mathrm{mmHg}$ below control, with corresponding increases in vascular capacity of 40,38 , and $66 \mathrm{ml}$. Thus, even when nitroglycerin decreases arterial resistance as much as $\mathrm{PGI}_{2}$, the increase in vascular capacity is substantially less. Despite the change in arterial resistance, there is not a significant redistribution of blood flow into the splanchnic system to account for the observed vascular capacity change. In response to nitroglycerin, hepatic vein flow changed by only $-13.8 \pm 15.4 \mathrm{ml} / \mathrm{min}$.

To investigate whether the initial increase in vascular capacity during nitroglycerin infusions might be mediated through a mechanism involving the rapid initial decline in arterial pressure and subsequent changes in baroreceptor stimulation, we denervated the carotid and aortic baroreceptors in two dogs. Infusions of nitroglycerin $(2 \mathrm{mg} / \mathrm{min})$ in these dogs resulted in increases in vascular capacity of 50 and $95 \mathrm{ml}$. In two other animals, after 150-mg mecamylamine ganglionic blockade, nitroglycerin, $2 \mathrm{mg}$ / min, resulted in volume gains of 40 and $150 \mathrm{ml}$. Therefore, carotid and aortic baroreceptors do not appear to mediate the increase in vascular capacity due to nitroglycerin.

We isolated and perfused 10 spleens to compare the vasodilating action of $\mathrm{PGI}_{2}$ with that of nitroglycerin and nitroprusside. When $\mathrm{PGI}_{2}$ was infused at $100 \mathrm{mcg} / \mathrm{min}$ for $5 \mathrm{~min}$, spleen weight increased by $9.0 \pm 2.4 \%(P<0.001)$. Infusions of nitroglycerin at $1 \mathrm{mg} / \mathrm{min}$ increased spleen weight by $3.6 \pm 2.2 \%(P$ $<0.001$ ), and nitroprusside infused at $400 \mathrm{mcg} / \mathrm{min}$ increased spleen weight by $3.5 \pm 2.3 \%(P<0.001)$. The mean increase in weight during infusions with $\mathrm{PGI}_{2}$ was significantly greater than were the mean increases during infusions of either nitroglycerin or nitroprusside $(P<0.001)$.

\section{Discussion}

Infusion of prostacyclin is associated with a marked increase in total intravascular capacity. This increase occurs in both the splanchnic and extrasplanchnic capacity vasculature and appears secondary to an effect of $\mathrm{PGI}_{2}$ on vascular smooth muscle. Furthermore, in the canine models studied, $\mathrm{PGI}_{2}$ increases vascular capacity significantly more than nitroglycerin, which has, to date, been considered one of the most potent venodilating agents available $(28,29)$.

With regard to the site of action of $\mathrm{PGI}_{2}$ in increasing vascular capacity, recent studies have demonstrated that one mechanism of altering vascular capacity in the dog is through increased or decreased transhepatic vascular resistance, with resultant changes in splanchnic vascular capacity $(28,29)$. Acetylcholine, for example, increases transhepatic resistance to blood flow resulting in portal venous pooling (29), whereas isoproterenol decreases transhepatic resistance, allowing blood from the portal venous circulation to enter the central circulation (28). Transhepatic resistance did not change significantly during infusions of $\mathrm{PGI}_{\mathbf{2}}$. Thus, this mechanism did not account for the increase in vascular capacity due to $\mathrm{PGI}_{2}$. To determine whether the splanchnic cir- 


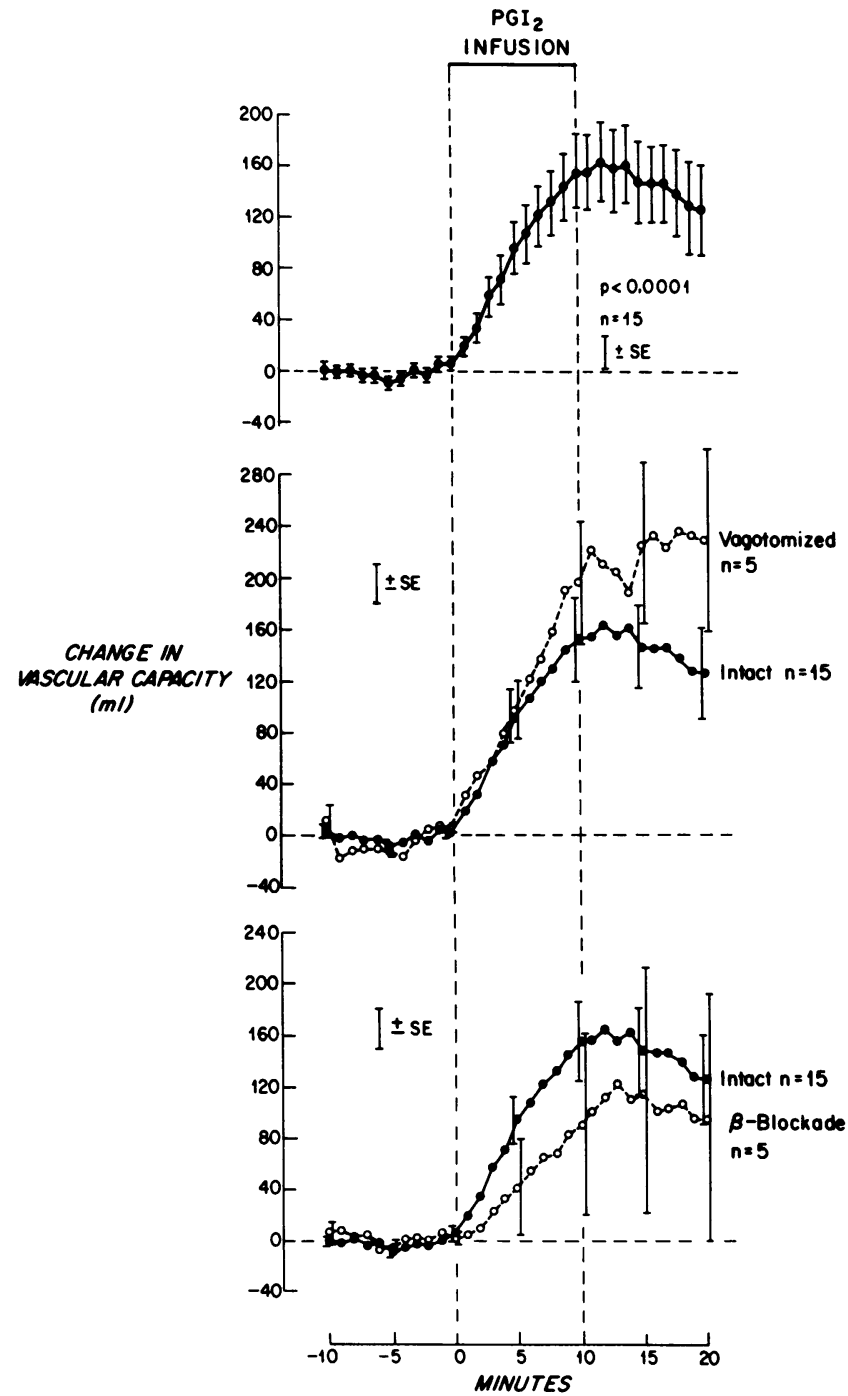

Figure 4. (Top) Mean data on the effect of 10-min infusions on vascular capacity in 15 animals. Vascular capacity increased at the beginning of the infusion, reaching a mean increase in capacity of $155 \mathrm{ml}$ at the end of the infusion period. (Middle and Bottom) Comparison of the changes in vascular capacity during infusions of $\mathrm{PGI}_{2}$ in vagotomized and beta adrenergic-blocked animals to changes in 15 animals. Neither bilateral cervical vagotomy nor beta adrenergic blockade significantly reduced the increase in vascular capacity due to $\mathrm{PGI}_{2}$.

culation played any role in the increase in vascular capacity, $\mathrm{PGI}_{2}$ was infused into eviscerated animals. The results demonstrated that $\mathbf{P G I}_{2}$ acts on splanchnic as well as extrasplanchnic capacity vasculature, and that the splanchnic vasculature accounts for roughly one-half of the total increase in vascular capacity.

Chapple et al. $(30,31)$ have reported that $\mathrm{PGI}_{2}$ through vagal stimulation results both in bradycardia, which can be abolished by atropine, and in hypotension, which is reversible by vagotomy. Because vagal stimulation increases total vascular capacity (24), we infused $\mathrm{PGI}_{2}$ after bilateral cervical vagotomy. The increase in vascular capacity did not diminish after vagotomy; thus, $\mathbf{P G I}_{2}$ does not increase vascular capacity by vagal stimulation.

While infusion of isoproterenol decreases total vascular capacity (23), beta adrenergic receptor stimulation regionally dilates

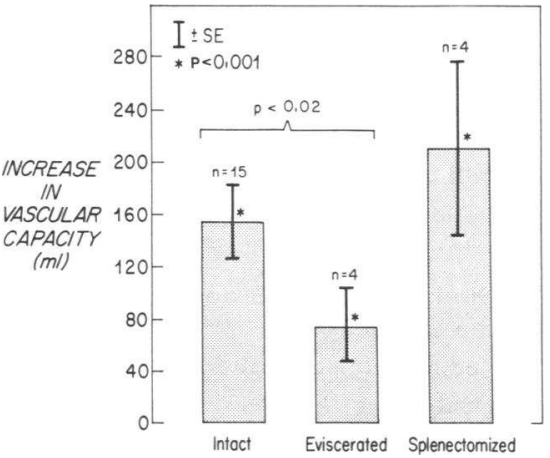

Figure 5. Comparison of the effect of intra-arterial infusions of prostacyclin on vascular capacity in the 15 intact animals to that of four animals that were eviscerated and to that of four animals that were splenectomized. Removal of the splanchnic organs significantly reduced $(P<0.02)$, but did not eliminate, the increase in capacity. Splenectomy alone did not significantly change the increase in capacity due to $\mathrm{PGI}_{2}$. Increases in vascular capacity were significantly above control capacity in each group $(P<0.001)$.

certain areas of the venous system (32-34). This raised the possibility that $\mathbf{P G I}_{2}$ increases vascular capacity through beta adrenergic stimulation of some areas of the capacitance vasculature. To investigate this possibility, we infused $\mathrm{PGI}_{2}$ after beta adrenergic blockade. The mean increase in vascular capacity in these experiments did not differ significantly from that in the control preparations, which indicated that $\mathbf{P G I}_{2}$ increases vascular capacity by a mechanism other than beta adrenergic receptor

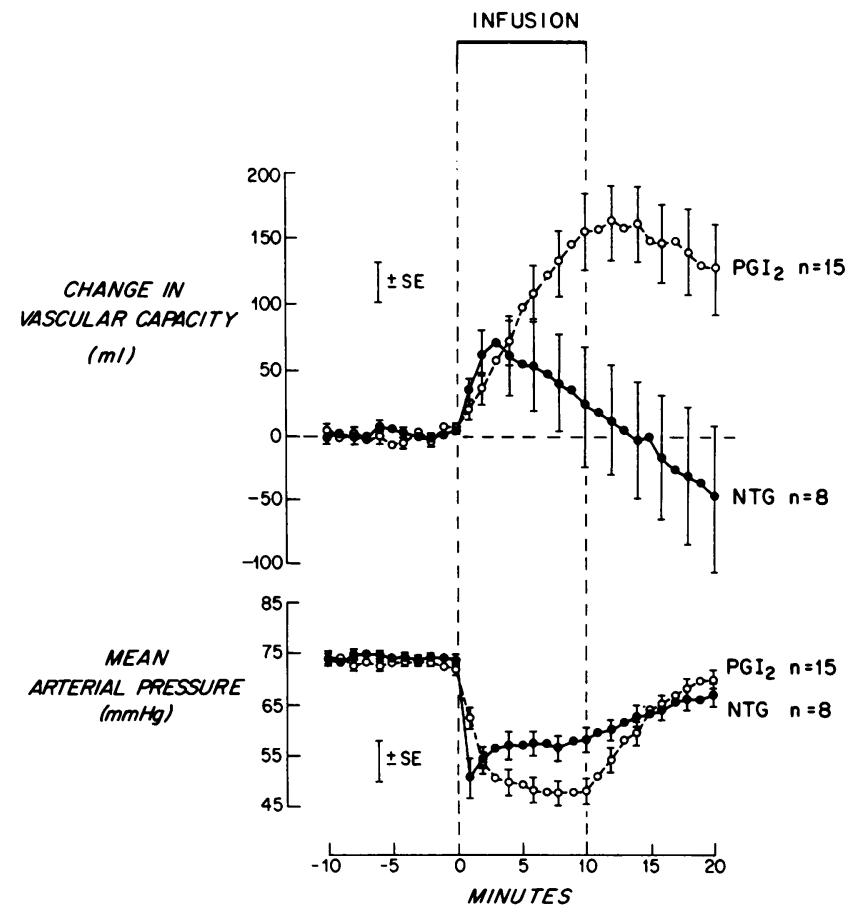

Figure 6. Comparison of the changes in vascular capacity and arterial pressure during infusions of $\mathrm{PGI}_{2}$ in 15 animals to changes in these parameters during infusions of nitroglycerin (NTG) in eight animals. The two drugs produced a similar decrease in arterial pressure, while the increase in capacity at the end of the infusion due to prostacyclin was significantly greater $(P<0.02)$ than the increase in capacity due to NTG. 
stimulation. The evidence presented thus far suggests that $\mathrm{PGI}_{2}$ increases vascular capacity through an action on vascular smooth muscle. An alternative explanation for the apparent change in vascular capacity is an increase in capillary permeability, which would permit transudation of plasma into extravascular spaces, decreasing the blood volume available to the central circulation. Evidence provided by the present study against increased capillary permeability as the sole explanation is the observation that $\mathrm{PGI}_{2}$ dilates the vascular smooth muscle of the isolated spleen. Opdyke and Ward (35) have demonstrated that the isolated spleen can serve as a model for investigation of the changes in the smooth muscle of the capacitance vasculature. We used an isolated, separately perfused spleen model to compare the effects of $\mathrm{PGI}_{2}$ with those of two other vasodilating agents. Our results indicate that $\mathrm{PGI}_{2}$ is a more potent vasodilating agent than is nitroglycerin or nitroprusside. Although the mechanism of action of $\mathrm{PGI}_{2}$ on vascular smooth muscle has not been determined, it has been shown that $\mathrm{PGI}_{2}$ increases cyclic AMP in platelets and colonic epithelium by a mechanism involving a specific $\mathrm{PGI}_{2}$ receptor $(36,37)$; a similar effect could account for the action of $\mathrm{PGI}_{2}$ on vascular smooth muscle. Therefore, existing evidence supports a direct action of $\mathrm{PGI}_{2}$ on vascular smooth muscle, although further studies are necessary to define the precise biochemical action by which $\mathbf{P G I}_{2}$ increases vascular capacity.

Several studies have shown that $\mathrm{PGI}_{2}$ relaxes a number of different vascular preparations; however, one study has reported that isolated strips of rat portal vein weakly constricted when incubated with $\mathrm{PGI}_{2}(38)$. The same study also found that $\mathrm{PGI}_{2}$ failed to either relax or constrict isolated human saphenous vein. Veins comprise the major portion of the capacitance vasculature, but venules are considered more important to changes in capacity than are large veins, such as the portal or saphenous veins (39). Thus, $\mathrm{PGI}_{2}$ may not relax some in vitro preparations of large veins, but it is a potent dilator of overall capacitance vasculature in the dog.

The dose of $\mathrm{PGI}_{2}$ that has been employed in canine studies has been substantially higher than that used in clinical studies. For example, in a study on coronary artery patency in the dog (40) and in a study on nutrient perfusion in the canine brain (41), the dosages of $\mathrm{PGI}_{2}$ employed were 20-25 times those used by Zusman and coworkers $(7,8)$ in their investigation of the antiplatelet effect of $\mathrm{PGI}_{2}$ in patients undergoing hemodialysis. The maximum dosage employed by Zusman (8) was $8 \mathrm{ng} / \mathrm{kg}$ per min. It is of interest that in the clinical study of the effects of $\mathrm{PGI}_{2}$ on congestive heart failure by Yui and coworkers (22), a mean dose of $22 \mathrm{ng} / \mathrm{kg}$ per min was necessary to produce decreases in mean arterial pressure of $23 \mathrm{mmHg}$. In the present study, the infusion rate of $\mathrm{PGI}_{2}$ of $10 \mathrm{mcg} / \mathrm{min}$ produced approximately the same decrease in mean arterial pressure as this latter clinical study. This rate of delivery, not taking into account hemodilution by blood from two donor dogs in the extracorporeal circuit, is $\sim 22$ times that employed by Yui (22). If, for the same decrease in blood pressure, the findings in dogs are representative of those in man, similar changes in venous capacity should occur in the human. However, the exact magnitude of the changes in venous capacity in the human with $\mathrm{PGI}_{2}$ remains to be determined, and caution must be exercised in comparing effects across species due to the differences in dosages needed to demonstrate similar arterial effects.

$\mathrm{PGI}_{2}$ and nitroglycerin produced markedly different effects on both the magnitude and time-course of action of changes in vascular capacity. Vascular capacity increased for the entire period of $\mathrm{PGI}_{2}$ infusion, and then returned toward the control level of capacity. While $\mathbf{P G I}_{2}$ has been implicated as a mediator for certain actions of nitroglycerin on vascular preparations (4244), the disparity of action of nitroglycerin and $\mathrm{PGI}_{2}$ on both the magnitude and time course of change in vascular capacity suggests that nitroglycerin may change vascular capacity in the present study by a mechanism other than through the release of endogenous $\mathrm{PGI}_{2}$. This finding is consistent with the recent work by Bennett et al. (45), which demonstrated that nitroglycerin-induced relaxation of isolated rabbit celiac and mesenteric arterial rings appears to be mediated through a mechanism other than stimulation of $\mathrm{PGI}_{2}$ synthesis. It is known that coronary arteries develop tolerance to the vasodilating action of nitroglycerin (46), and that patients who have previously received isosorbide dinitrate develop a cross-tolerance to nitroglycerin (47). The greater the effect of $\mathrm{PGI}_{2}$ on vascular capacity, as well as the lack of a demonstration of tolerance development to $\mathrm{PGI}_{2}$, suggests the feasibility of clinical investigation in man to compare the effects on vascular capacity of $\mathrm{PGI}_{2}$ and nitroglycerin.

The action of $\mathrm{PGI}_{2}$ on vascular capacity has several important clinical implications. First, additional volume may be required to maintain hemodynamic stability in patients receiving $\mathrm{PGI}_{2}$, such as those on hemodialysis $(7,8)$ or in whom extracorporeal membrane oxygenation is employed (4-6). Second, $\mathrm{PGI}_{2}$ may be valuable in conditions in which an increase in vascular capacity is desired, as in the treatment of severe congestive heart failure that is refractory to conventional therapy (22). A substantial part of this salutory effect may be due to a reduction in preload that is secondary to an increase in intravascular capacity rather than solely secondary to a reduction of systemic vascular resistance. Prostacyclin may not only be safe to use in patients with severe congestive failure due to ischemic heart disease, but may actually exert a protective effect on ischemic myocardium. Bergman and coworkers (48) have shown that intravenous $\mathrm{PGI}_{2}$ increases mean atrial pacing time to clinical angina and increases the lactate extraction ratio. Not only, as shown in the present study, may $\mathrm{PGI}_{2}$ protect ischemic myocardium by decreasing venous return, ventricular wall tension, and thus myocardial oxygen consumption, but, as shown by Lefer et al. (49), $\mathrm{PGI}_{2}$ administered intravenously decreases the mean arterial pressure, and hence the tension time index, without increasing heart rate. Dusting and coworkers (50) and Einzig and coworkers (51) have both shown that $\mathrm{PGI}_{2}$ induces coronary vasodilatation in anesthetized dogs. $\mathrm{PGI}_{2}$ may also preserve ischemic myocardium by preventing the adhesion and aggregation of platelets in atherosclerotic coronary arteries. Furthermore, Araki and Lefer (52) have demonstrated that $\mathbf{P G I}_{2}$ has a direct cytoprotective effect in ischemic myocardium which is independent of its inhibitory effect on platelet aggregation, its effect on lowering systemic blood pressure, and its effect on producing coronary vasodilatation (52). Thus, the present finding that $\mathrm{PGI}_{2}$ has the potential of reducing preload may find wide clinical application.

\section{Acknowledgments}

The authors wish to acknowledge the expert technical assistance of Mr. Luis Guerrero and Mr. George Hodakowski. The authors are grateful for the capable secretarial assistance of Ms. Dyann Inniss. We also thank the Burrows Wellcome Co., Durham, NC, and the Upjohn Co., Kalamazoo, MI, for the supplies of prostacyclin, and Merck, Sharpe \& Dohme for mecamylamine. 
This work was supported by grants from the Educational Foundation of America, Inc., and from the National Heart, Lung and Blood Institute (HL-32796, HL-07208, and HL-26215).

\section{References}

1. Bunting, S., R. Gryglewski, S. Moncada, and J. R. Vane. 1976. Arterial walls generate from prostaglandin endoperoxides a substance (prostaglandin $\mathrm{X}$ ) which relaxes strips of mesenteric and coelic arteries and inhibits platelet aggregation. Prostaglandins. 12:897-913.

2. Moncada, S., and J. R. Vane. 1978. Pharmacology and endogenous roles of prostaglandin endoperoxides, thromboxane $\mathrm{A} 2$ and prostacyclin. Pharmacol. Rev. 30:293-331.

3. Coppe, D., T. Wonders, M. Snider, and E. W. Salzman. 1979. Preservation of platelet number and function during extracorporeal membrane oxygenation by regional infusion of prostacyclin. In Prostacyclin. J. R. Vane and S. Bergstrom, editors. Raven Press, New York, 371-383.

4. Faichney, A., K. G. Davidson, D. J. Wheatley, J. F. Davidson, and I. D. Walker. 1982. Prostacyclin in cardiopulmonary bypass operations. J. Thorac. Cardiovasc. Surg. 84:601-608.

5. Rådegran, K., C. Aren, and A. Teger-Nilsson. 1982. Prostacyclin infusion during extracorporeal circulation for coronary bypass. J. Thorac. Cardiovasc. Surg. 83:205-211.

6. Aren, C., K. Feddersen, and K. Rådegran. 1983. Effects of prostacyclin infusion on platelet activation and postoperative blood loss in coronary bypass. Ann. Thorac. Surg. 36:49-54.

7. Zusman, R. M., R. H. Rubin, A. E. Cato, D. M. Cocchetto, J. W. Crow, and N. Tolkoff-Rubin. 1981. Hemodialysis using prostacyclin instead of heparin as the sole antithrombotic agent. N. Engl. J. Med. 304(16):934-939.

8. Zusman, R. M., J. W. Crow, A. E. Cato, and N. Tolkoff-Rubin. 1981. Effects of prostacyclin infusion in uremic patients: hematologic and hemodynamic responses. Clin. Pharmacol. Ther. 30:251-257.

9. Dusting, G. J., S. Moncada, and J. R. Vane. 1977. Prostacyclin (PGX) is the endogenous metabolite responsible for relaxation of coronary arteries induced by arachidonic acid. Prostaglandins. 13:3-15.

10. Boullin, D. J., S. Bunting, W. P. Blasco, T. M. Hunt, and S. Moncada. 1979. Response of human and baboon arteries to prostaglandin endoperoxides and biologically generated and synthetic prostacyclin: their relevance to cerebral arterial spasm in man. Br. J. Clin. Pharmacol. 7: 139-147.

11. Szczeklik, J., A. Szczeklik, and R. Nizankowski. 1980. Prostacyclin for pulmonary hypertension. Lancet. II:1076. (Abstr.)

12. Watkins, W. D., M. B. Peterson, R. K. Crone, D. C. Shannon, and L. Levine. 1980. Prostacyclin and prostaglandin El for severe idiopathic pulmonary artery hypertension. Lancet. I:1083. (Abstr.)

13. Borchent, J., J. Franke, and J. Lichey. 1980. Reduction of acute pulmonary hypertension by prostacyclin. Cor Vasa. 4:281-287.

14. Rubin, L. J., B. M. Groves, J. T. Reeves, M. Frosolono, F. Handel, and A. E. Cato. 1982. Prostacyclin-induced acute pulmonary vasodilation in primary pulmonary hypertension. Circulation. 66:334-338.

15. Carlson, L. A., and A. G. Olsson. 1976. Intravenous prostaglandin E1 in severe peripheral vascular disease. Lancet. II:810.

16. Szczeklik, A., R. Nizankowski, S. Skawinski, J. Szczeklik, P. Gluszko, and R. J. Gryglewski. 1979. Successful therapy of advanced arteriosclerosis obliterans with prostacyclin. Lancet. I:111-114.

17. Dembinska-Kiec, A., T. Gryglewska, A. Zmuda, and R. J. Gryglewski. 1977. The generation of prostacyclin by arteries and by the coronary vascular bed is reduced in experimental atherosclerosis in rabbit. Prostaglandins. 14:1025-1034.

18. A. Szczeklik, R. J. Gryglewski, R. Zizankowski, S. Skawinski, P. Gluszko, and R. Korbut. 1980. Prostacyclin therapy in peripheral arterial disease. Thromb. Res. 19:191-199.

19. Belch, J. J. F., B. McArdle, J. G. Pollock, C. D. Forbes, A. McKay, P. Leiberman, G. D. O. Lowe, and C. R. M. Prentice. 1983. Epoprostenol (prostacyclin) and severe arterial disease. A double blind trial. Lancet. I:315-317.
20. Pitt, B., M. J. Shea, J. L. Romson, and B. R. Lucchesi. 1983. Prostaglandins and prostaglandin inhibitors in ischemic heart disease. Ann. Intern. Med. 99:83-92.

21. Jentzer, J. H., E. H. Sonnenblick, and E. S. Kirk. 1979. Coronary and systemic vasomotor effects of prostacyclin: implication for ischemic myocardium. In Prostacyclin. J. R. Vane and S. Bergstrom, editors. Raven Press, New York. 323-338.

22. Yui, Y., H. Nakajima, C. Kawai, and T. Murakami. 1982. Prostacyclin therapy in patients with congestive heart failure. Am. J. Cardiol. 50:320-324.

23. Rutlen, D. L., E. W. Supple, and Wm. J. Powell, Jr. 1981. $\beta$-Adrenergic regulation of total systemic intravascular volume in the dog. Circ. Res. 48(1):112-120.

24. Supple, E. W., and Wm. J. Powell, Jr. 1981. Effect of acetylcholine on vascular capacity in the dog. J. Clin. Invest. 68:64-74.

25. Snedecor, G. W., and W. G. Cochran. Regression. Statistical Methods. 1971. Iowa State University Press, Ames, IA. Sixth ed. 135171.

26. Snedecor, G. W., and W. G. Cochran. The comparison of two samples. Statistical Methods. 1971. Iowa State University Press, Ames, IA. Sixth ed. 91-119.

27. Dixon, W. J., M. B. Brown, L. Engleman, J. W. Frane, M. A. Hill, R. I. Jennrich, and J. D. Toporek. 1981. BMDP Statistical Software. University of California Press, Berkeley.

28. Miller, R. R., L. A. Vismara, D. O. Williams, E. A. Amsterdam, and D. T. Mason. 1976. Pharmacological mechanisms for left ventricular unloading in clinical congestive heart failure. Circ. Res. 39(1):127-133.

29. Cohn, J. N., and J. A. Franciosa. 1977. Vasodilator therapy of cardiac failure. N. Engl. J. Med. 297(1):27-31.

30. Chapple, D. J., G. J. Dusting, R. Hughes, and J. R. Vane. 1978. A vagal reflex contributes to the hypotensive effect of prostacyclin in anesthetized dogs. J. Physiol. (Lond.). 281:43-44.

31. Chapple, D. J., G. J. Dusting, R. Hughes, and J. R. Vane. 1978. Some direct and reflex cardiovascular actions of prostacyclin $\left(\mathrm{PGI}_{2}\right)$ and $\mathrm{PGE}_{2}$ in anaesthetized dogs. Br. J. Pharmacol. 68:437-447.

32. Abboud, F. M., J. W. Eckstein, and B. G. Zimmerman. 1965. Venous and arterial responses to stimulation of beta adrenergic receptors. Am. J. Physiol. 209:383-389.

33. Folkow, B. 1960. Effects of catecholamines on consecutive vascular sections. In Adrenergic Mechanisms. J. R. Vane, G. E. W. Wolstenholme, and M. O'Connor, editors. Little, Brown \& Co., Boston. 190-198.

34. Webb-Peploe, M. M., and J. T. Shepherd. 1969. Beta receptor mechanisms in the superficial limb veins of the dog. J. Clin. Invest. 48: 1328-1335.

35. Opdyke, D. F., and C. J. Ward. 1973. Spleen as an experimental model for the study of vascular capacitance. Am. J. Physiol. 225(6): 1416-1420.

36. Simon, B., H. Kather, and B. Kommerell. 1978. Prostacyclin: a potent activator of human colonic adenylate cyclase activity. Z. Gastroenterol. 16(12):748-751.

37. Blair, I. A., and J. MacDermot. 1981. The binding of [3H]-prostacyclin to membranes of a neuronal somatic hybrid. Br. J. Pharmacol. 72(3):435-441.

38. Levy, J. 1978. Contractile responses to prostacyclin $\left(\mathrm{PGI}_{2}\right)$ of isolated human saphenous and rat venous tissue. Prostaglandins. 16(1): 93-97.

39. Folkow, B., and E. Neil. 1971. Circulation. Oxford University Press, New York. 466-493.

40. Aiken, J. W., R. R. Gorman, and R. J. Shebuski. 1979. Prostacyclin prevents blockage of partially obstructed coronary arteries. In Prostacyclin. J. R. Vane and S. Bergstrom, editors. Raven Press, New York. 311-321.

41. Hallenbeck, J. M., and T. W. Furlow. 1979. Prostaglandins influence nutrient perfusion in brain during the postischemic period. In Prostacyclin. J. R. Vane and S. Bergstrom, editors. Raven Press, New York. 299-310. 
42. Levin, R. I., E. A. Jaffee, B. B. Weksler, and K. Tack-Goldman. 1981. Nitroglycerin stimulates synthesis of prostacyclin by cultured human endothelial cells. J. Clin. Invest. 67:762-769.

43. Ouyang, P., and P. R. Reid. 1981. Specificity of ibuprofen inhibition of coronary vasodilatation by nitroglycerin. Circulation. 64(4): 71. (Abstr.)

44. Schror, K., L. Grodzinska, and H. Darius. 1981. Stimulation of coronary vascular prostacyclin and inhibition of human platelet thromboxane A2 after low-dose nitroglycerin. Thromb. Res. 23:59-67.

45. Bennett, B. M., J. A. Moffat, P. W. Armstrong, and G. S. Marks. 1983. Investigation of the role of prostaglandins in nitroglycerin-induced relaxation of isolated rabbit blood vessels. Can. J. Physiol. Pharmacol. 61:554-560.

46. Needleman, P., and E. M. Johnson, Jr. 1973. Mechanism of tolerance development to organic nitrates. J. Pharmac. Exp. Ther. 184(3): 709-715.

47. Zelis, R., and D. T. Mason. 1975. Isosorbide dinitrate: effect on the vasodilator response to nitroglycerin. J. Am. Med. Assoc. 234(2): $166-170$.
48. Bergman, G., L. Atkinson, P. J. Richardson, K. Daly, M. Rothman, G. Jackson, and D. E. Jewitt. 1981. Prostacyclin: haemodynamic and metabolic effects in patients with coronary artery disease. Lancet. I: 569-577.

49. Lefer, A. M., M. L. Ogletree, J. B. Smith, M. J. Silver, K. C. Nicolaou, W. E. Barnette, and G. P. Gasic. 1978. Prostacyclin: a potentially valuable agent for preserving myocardial tissue in acute myocardial ischemia. Science (Wash. DC). 200:52-54.

50. Dusting, G. J., D. J. Chapple, R. Hughes, S. Moncada, and J. R. Vane. 1978. Prostacyclin $\left(\mathbf{P G I}_{2}\right)$ induces coronary vasodilatation in anaesthetized dogs. Cardiovasc. Res. 12:720-730.

51. Einzig, S., R. Sotomora, G. H. R. Rao, J. M. Gerrard, J. E. Foker, and J. G. White. 1980. Effect of low dose prostacyclin infusion on blood flow in acutely ischemic canine myocardium. Prostaglandins Med. 5(3): 209-219.

52. Araki, H., and A. M. Lefer. 1980. Role of prostacyclin in the preservation of ischemic myocardial tissue in the perfused cat heart. Circ. Res. 47:757-763. 